\section{Cambios cuantitativos en la microflora oral de pacientes alimentados a través de sondas transnasales}

\author{
Quantitative changes in the oral microflora of patients fed by \\ transnasal tubes
}

Artículo Original

Maira Alejandra Chávarri Vásquez ${ }^{1}$, Erick Mestanza Tejada', Taylor Purca Peña ${ }^{1}$, Isabel San Román Suarez1, Víctor David Mamani Ticona², Oscar Aldazabal Orue ${ }^{2}$, Rudy Cesar Canchuricra Ramos²,

1. Cirujano Dentista. Universidad Nacional Mayor de San Marcos, Lima, Perú.

2. Bachiller en Odontología. Universidad Nacional Mayor de San Marcos, Lima, Perú.

Correspondencia

C.D. Maira Alejandra Chávarri Vásquez. Jr. Nevado Pancani 270. Lima 36. Perú Correo electrónico:

mairitaalejandra@hotmail.com
Fecha de recepción: 05-08-13 Fecha de aceptación: 20-06-14

\section{Introducción}

A lo largo de la historia, el ser humano ha cuidado de su alimentación como medio instintivo de supervivencia, es por ello que esta necesidad básica es cubierta desde el nacimiento a través del amamantamiento, y a lo largo de la vida a través de la alimentación oral.

Sin embargo hay situaciones, que el ser humano requiere de soporte nutricional artificial, generalmente esto se da cuando somos víctimas de una patología que impide o limita severamente la nutrición normal, formando esta parte del tratamiento 5 .
Existen 2 tipos de rutas para administrarse la nutrición artificial, estos son la nutrición enteral y la nutrición parenteral, siendo la primera opción la más utilizada por ser la más fisiológica, de mayor sencillez, con complicaciones menos graves y de menor costo con respecto a la nutrición parenteral ${ }^{5}$.

La nutrición enteral a través de sondas se emplea en pacientes cuya alimentación por vía oral no es posible, ya sea debido a transtornos neurológicos o mecánicos, pero el tracto gastrointestinal es anatómica y funcionalmente útil, ya sea parcial o totalmente ${ }^{1,2,5}$.
Este medio elimina la necesidad de formar el bolo alimenticio en boca, lo que implica la reducción de volumen salival por falta de estimulo y que la microflora bacteriana carezca de sustrato para su metabolismo y desarrollo.

El objetivo de este estudio ha sido evaluar la microflora de la cavidad oral en pacientes que reciben alimentación por vía enteral con respecto a otros que reciben una dieta normal por vía oral, para ello se trabajo con el estreptococo y la cándida albicans por ser la bacteria y el hongo, respectivamente, más abundante en cavidad oral. 
La finalidad es evidenciar que la ausencia de alimentación por vía oral es causa suficiente para una modificación en la cantidad de microorganismos que conforman el biofilm de la cavidad oral.

Cabe destacar que el presente estudio tiene pocos antecedentes realizados a nivel mundial, por lo cual es de mucha importancia para un adecuado plan de tratamiento en este tipo de pacientes, debido a esto se recomienda realizar estudios similares posteriormente.

\section{Materiales y método}

Se realizó un estudio descriptivo comparativo. El estudio se realizó en las salas de medicina interna y cirugía del Hospital Nacional Dos de Mayo, Lima - Perú durante el mes de Octubre de 2011. El trabajo fue aprobado por el comité de ética de dicho hospital.

Se seleccionaron 15 pacientes con alimentación enteral a través de sondas transnasales, grupo de estudio y 15 pacientes con alimentación por vía oral grupo control, siendo estos últimos elegidos basándose en la igualdad de rango de edad, sexo, condición de salud oral y presencia o no de terapia antibiótica y/o corticoide, en relación a los pacientes del grupo estudio.

Los criterios de exclusión fueron: pacientes menores de 18 ańos, pacientes diabéticos, pacientes portadores de VIH/ SIDA, pacientes que reciben quimioterapia, pacientes transplantados, pacientes con medicación de agentes inmunosupresores.

En todos los pacientes se obtuvo los siguientes datos: consentimiento informado, edad, sexo, diagnóstico, terapia medicamentosa, odontograma e índice de higiene oral.

Se tomo muestras de fondo de surco, mediante hisopado, en los pacientes previamente seleccionados. El transporte de las muestras se realizó en caldo de Tioglicolato Stuart, teniendo un tiempo aproximado de $30-60$ minutos hasta el momento de la siembra. El aislamiento microbiológico se realizó en medios Agar mitis salivarius (estreptococos) y Agar Saboraud (candida).

Todos los datos recogidos post cultivo microbiológico fueron consignados en una tabla general de datos y resultados para facilitar su tabulación. El análisis de las variables se realizó mediante chi cuadrado, estableciéndose el nivel de confianza en el 95\% ( $\mathrm{p}<0.05)$ para estreptococos y en el 99.5\% ( $p<0.005)$ para candida, además se hallo la oportunidad relativa, fracción atribuible en expuestos, fracción atribuible en no expuestos y fracción atribuible en población.

\section{Resultados}

De las 15 placas petri conteniendo Agar mitis salivarius para crecimiento bacteriano de estreptococos en muestras de pacientes portadores de sondas transna- sales, 10 presentaron crecimiento abundante $(66.7 \%)$, en comparación de las $4(26.7 \%)$ que presentaron crecimiento abundante en muestras de pacientes con alimentación a través de vía oral, (fig.1).

De igual modo, de las 15 placas petri conteniendo Agar Saboraud para crecimiento micótico de candida en muestras de pacientes portadores de sondas transnasales, 11 presentaron crecimiento abundante $(73.3 \%)$, en comparación de las $2(13.3 \%)$ que presentaron crecimiento abundante en muestras de pacientes con alimentación a través de vía oral, (fig.2).

Se pudo determinar mediante chi cuadrado, que existe relación positiva entre uso de sondas transnasales y el incremento de estreptococos $(\mathrm{p}<0.05)$ y candida $(\mathrm{p}<0.005)$.

Además, al hallar la oportunidad relativa, se pudo identificar que existe 5.5 más posibilidades que los pacientes con alimentación a través de sondas transnasales presenten mayor crecimiento bacteriano por estreptococos en comparación de los pacientes con alimentación por vía oral; y 17.87 más posibilidades de que presenten mayor crecimiento micótico por candida.

Al compararse las frecuencias de mayor crecimiento micótico y bacteriano en pacientes con alimentación a través de sondas transnasal, se hallo que fue similar obteniéndose una frecuencia de $66.7 \%$ para estreptococos y $73.3 \%$ para candida.

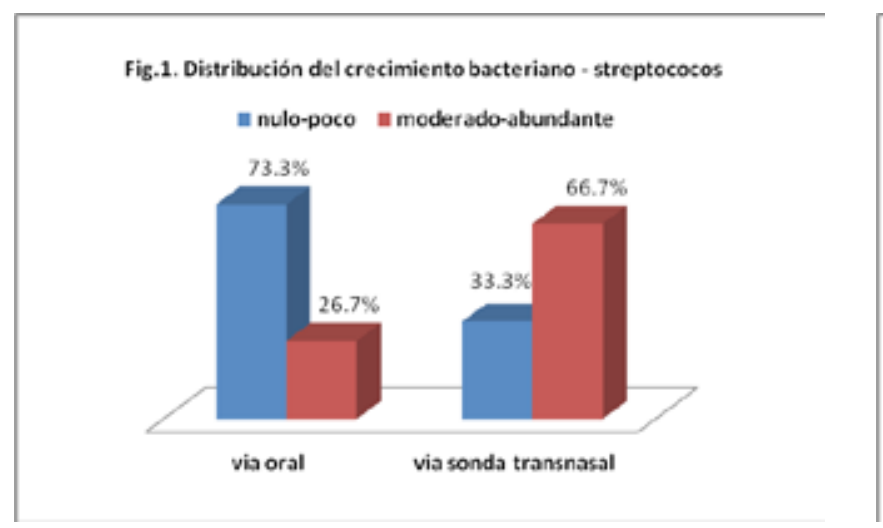

\section{Discusión}

El propósito de este estudio fue evaluar y comparar la relación entre la alimentación a través de vía transnasal con la variación en la cantidad de microflora de fondo de surco de cavidad oral.

De los resultados obtenidos se halló que la frecuencia de mayor crecimiento bacteriano y micótico difiere significativamente para los pacientes con alimentación a través de vía transnasal y los pacientes con alimentación por vía oral, siendo mayor en el primer grupo.

Estos resultados concuerdan en cierta medida con los trabajos de investigación realizados por Leibovitz y colaboradores entre los años 2003-2005. Estos trabajos de investigación aunque no trabajaron con estreptococos
Fig.2. Distribución del crecimiento micótico - càndida

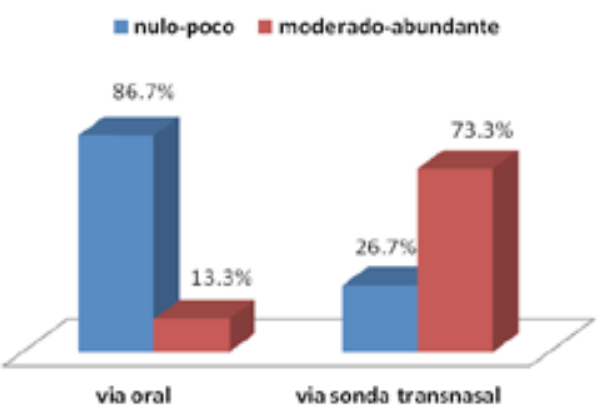

y candida, si reportaron un mayor incremento de microorganismos, principalmente bacterias de tipo staphilococos, en zona de boca y faringe $e^{6,7,8,9}$.

La posibilidad que la medicación recibida por los pacientes y/o problemas sistémicos influyera en estos resultados es poco probable, debido a que el grupo control poseía similares características sistémicas y medicación similar al grupo de trabajo. 
Según Palmer, los cambios en el medio oral pueden ser producto de la disminución de la producción salival; por el contrario Leibovitz no encontró diferencia significativa en la secreción salival basal e inducida entre los dos grupos de pacientes. En el presente estudio, clínicamente, se pudo observar una gran diferencia en la producción de saliva, siendo mucho menor en pacientes con sonda nasogástrica. ${ }^{7,10}$

Leibovitz, realizó un estudio para determinar diferencias entre los componentes salivales de estos grupos que pudiera explicar la mayor colonización de la orofaringe en pacientes con sonda nasogástrica y encontró que de doce componentes estudiados, solo el acido úrico era significativamente diferente, siendo $50 \%$ menor en pacientes con sonda nasogástrica. Al ser el acido úrico, según varios autores, el principal antioxidante salival y esta función estar relacionada con la actividad antimicrobiana, explicaría en cierta manera no solo la mayor colonización de la orofaringe en este grupo de pacientes, sino también la mayor colonización oral. ${ }^{3,4,8}$

\section{Conclusiones}

1. En general, existe relación positiva, entre el uso de sondas transnasales como medio de alimentación de los pacientes y la mayor proliferación de estreptococos y candida albicans en la microflora oral.

2. Existe 5.5 más posibilidades que los pacientes con alimentación a través de sondas nasogastricas presenten mayor crecimiento de estreptococos y 17.87 que presenten mayor crecimiento micótico de candida, en comparación de los pacientes con alimentación por vía oral.

\section{Agradecimiento}

Nuestro más sincero agradecimiento al Hospital Nacional Dos de Mayo, Servicios de medicina interna y cirugía, Lima - Perú, por permitir la realización del presente trabajo en sus salas de hospitalización y en especial a cada uno de los pacientes.

\section{Referencias bibliográficas}

1. Astiasaran I, Lasheras B, Ariño A, Martinez J. Alimentos y nutrición en la práctica sanitaria. Ediciones Diaz de Santos. Madrid-España. 397-407p.

2. Castillo M, Yanyachi M. Evaluación de la calidad higiénica sanitaria en fórmulas de nutrición enteral usadas en dos hospitales de la ciudad de Lima. [Tesis para optar al título de químico farmacéutico]. Facultad de Farmacia y bioquímica. Universidad Nacional Mayor de San Marcos. 2002.

3. Diab - Ladki R, Pellat B, Chahine $R$. Decrease in the total antioxidant activity of saliva in patients with periodontal disease. Clin Oral Invest 2003;7:103-107.

4. Gibson G, Barrett E. The role of salivary function on oropharyngeal colonization. Spect Care Dent 1992;12(4):153-6.
5. Hernández A, Álvarez J, Culebras J, García A. Tratado de Nutrición clínica. Tomo IV. 2aed. Madrid: Editorial Médica Panamericana. 2010. 119-130p.

6. Leibovitz, A, Plotnikov G, Habot B, Rosenberg M, Segal M. Pathogenic colonization of oral flora in frail elderly patients fed by nasogástrica tube or percutoneus enterogastric tube. J. Gerontol A. Biol. Sci Med. Sci .2003 Jan;58(1):52-5.

7. Leibovitz A, Plotnikov G, Habot B, Rosenberg M, Wolf A, Nagler R, Graf E, Segal R. Saliva secretion and oral flora in prolonged nasogastric tube-fed elderly patients. Isr. Med. Assoc. J.2003;5:329_ 332.

8. Leibovitz A, Nagler R, Plotnikov G, Habot B, Segal R. Biochemical, inmunological and enzymatic components of saliva in prolonged naso-gastric-fed elderly patients. Aging 2004; 16:457-460.

9. Leibovitz A. Efecto de varias preparaciones antimicrobianas en la flora patógena oral en pacientes de edad avanzada portadores de sonda nasogástrica. Rev Agentes antimicrobianos y quimioterapia. 2005 agost;8:3566p.

10. Palmer L, Albulak K, Fields S, Filkin AM, Simon S, Smaldone G. Oral clearance and pathogenic oropharyngeal colonization in the elderly. American Journal of respiratory and critical care medicine. 2001;164(3):464-468. 